\title{
Glucose tolerance tests in 200 patients with senile cataract
}

\author{
W. N. DUGMORE AND K. TUN \\ From the Victoria Hospital, Burnley, Lancashire
}

SUMmARY An account is given of asymptomatic diabetes mellitus. To determine the incidence in 200 patients with senile cataract 3 tests are described, namely, a modified standard glucose tolerance test, a provocative steroid glucose tolerance test, and a standard glucose tolerance test. Known diabetics and patients with a fasting blood glucose in excess of $5.5 \mathrm{mmol} / \mathrm{l}$ or glycosuria were excluded. Eighty-eight patients had an abnormal modified standard glucose tolerance test. Of these, 41 had an abnormal curve after a provocative steroid glucose tolerance test, and 30 had an abnormal curve after a standard glucose tolerance test. Forty-three of the 71 patients with abnormal curves had no glycosuria, although the blood glucose level exceeded an arbitrary renal threshold of $10 \mathrm{mmol} / \mathrm{l}$. Asymptomatic diabetes was diagnosed in patients of all age groups. It is concluded that glucose intolerance is common in patients with senile cataract who show no glycosuria and have a normal fasting blood sugar on routine examination.

Diabetes mellitus presents not only in a clinical, overt, or symptomatic form but also in an asymptomatic (chemical) form, usually demonstrable only by blood and urine tests following the ingestion of glucose. ${ }^{2}$ Minor abnormalities in glucose metabolism may sometimes be discovered only by administering steroids to an individual prior to a standard glucose tolerance test. ${ }^{23}$

The earlier definition of subclinical diabetes suggested by the World Health Organisation Committee were the synonyms 'asymptomatic', 'chemical', 'latent', and 'suspect diabetes'. ${ }^{4}$ Keen and Jarrett ${ }^{5}$ interpose between normal and pathological (or diabetic) values a category of 'impaired glucose tolerance' (IGT). They state that patients with sugar-free urine 1 hour after a standard glucose tolerance test are highly unlikely to have significant glucose intolerance. Furthermore they consider there is very little risk of the development of specific complications of diabetes in this group. Confusion may occur because of the different international criteria for the cut-off values in the diagnosis of diabetes mellitus based on an oral glucose tolerance test. $^{6}$ In adolescence the asymptomatic form of diabetes is characterised by abnormal glucose tolerance tests and is classified as maturity onset type diabetes of young people (MODY), and in these cases the oral glucose tolerance test was

Correspondence to $\mathrm{Mr} \mathrm{W}$. N. Dugmore, Department of Ophthalmology, Victoria Hospital, Thursby Road, Burnley BB10 3HP. considered superior to the intravenous route in the screening of early abnormalities in carbohydrates metabolism. ${ }^{1}$ No reports have appeared on the use of strictly defined parameters for the oral glucose screening of senile cataract patients to determine the incidence of asymptomatic diabetes.

Cataract is a known complication of diabetes mellitus. Patients with 'primary' cataract and senile cataract have been investigated by a standard glucose tolerance test, but an unreported number with a raised fasting blood sugar and glycosuria on preliminary investigations were included. ${ }^{7} 8$ Paufique and Michand ${ }^{9}$ described 14 asymptomatic diabetic patients with cataracts but did not state whether the cataracts were senile nor which glucose tolerance test was used. Caird et al. ${ }^{10}$ found $3 \%$ of patients who had a senile cataract extraction were undiagnosed diabetics. In this paper we report the results in 200 patients with senile cataract investigated for asymptomatic diabetes by means of a modified standard glucose tolerance test and, if positive, a provocative steroid glucose tolerance test or a standard glucose tolerance test.

\section{Patients and methods}

There were 124 females and 76 males, their ages ranging from 55 to 86 , who were diagnosed as senile cataract patients during a routine outpatient appointment over a period of 5 months at the Victoria Hospital, Burnley. One hundred and 
ninety-four patients had bilateral senile cortical lens opacities, and the binocular visual acuity with glasses was $6 / 18$ or less. Six patients had had an extraction of a senile cataract, and the visual acuity in the unoperated eye was $3 / 60$ or less. There was no further classification of the cataracts, and fundal changes were ignored because of the difficulty, or impossibility, of interpretation owing to impeded observation. Patients were selected for investigation solely on the diagnosis of senile cataract though known diabetics, and those showing glycosuria or a fasting blood sugar exceeding $5.5 \mathrm{mmol} / \mathrm{l}$ were excluded.

All patients had a diet containing $300 \mathrm{~g}$ of carbohydrate over a period of 3 days before the tests. Preliminary screening was by a modified standard glucose tolerance test. After a 12-hour fast a venous blood sugar was estimated by a modification of the Trinder AutoAnalyzer method; the patient drank $50 \mathrm{~g}$ of glucose and $1 \frac{1}{2}$ hours later another blood sugar was estimated. A second blood sugar of $5.9 \mathrm{mmol} / \mathrm{l}$ or less was considered normal. Patients with $6-8.9 \mathrm{mmol} / \mathrm{l}$ had a provocative steroid glucose tolerance test, and those with $9 \mathrm{mmol} / 1$ or more had a standard glucose tolerance test. The definition of the terminology was as described below:

(a) Senile cataract. A cataract was considered senile when congenital, complicated, traumatic, and known secondary causes were excluded.

(b) Normal standard glucose tolerance test curve. This curve showed a fasting blood sugar of 3.0-5.5 $\mathrm{mmol} / \mathrm{l}$. After half an hour, the 'peak', the blood sugar did not exceed $9 \mathrm{mmol} / \mathrm{l}$, and 1 hour later returned to a fasting level.

(c) Provocative steroid glucose tolerance test. In addition to a standard glucose tolerance test the patient was prescribed a tablet of prednisolone $10 \mathrm{mg}$ at $9 \mathrm{pm}$ and at $7 \mathrm{am}$ the next day, the latter tablet 2 hours before the first blood specimen.

(d) Normal provocative steroid glucose tolerance curve. This curve showed a fasting blood sugar of 3.0-5.5 mmol/1. The 'peak' was recorded at 1 hour and the blood sugar did not exceed $10.5 \mathrm{mmol} / \mathrm{l}$. One hour later it returned to $7 \mathrm{mmol} / 1$ or less.

(e) The equivalent of $1 \mathrm{mmol} / 1$ in milligrams per cent was obtained by multiplying one SI unit by 18 , and the renal threshold was an arbitrary $10 \mathrm{mmol} / \mathrm{l}$. Fig. 1 illustrates a normal standard glucose tolerance test curve, a chemical diabetic curve, and a normal provocative steroid glucose tolerance curve.

\section{Results}

One hundred and twelve patients $(56 \%)$ had a normal modified standard glucose tolerance test. Sixty-eight patients were females and 44 were males.



Fig. 1 Glucose tolerance curves.

Eighty-eight patients (44\%) had an abnormal modified standard glucose tolerance test, of whom 56 were females and 32 were males.

Fifty-six patients $(28 \%)$ had a provocative steroid glucose tolerance test; an abnormal curve was recorded in 41 patients, and they were classified as steroid sensitised chemical diabetics. Twenty-four patients were females and 17 were males. Twenty patients $(10 \%)$ with an abnormal curve showed no glycosuria.

Thirty-two patients $(16 \%)$ had a standard glucose tolerance test; an abnormal curve was recorded in 30 patients $(15 \%)$ and they were classified as chemical diabetics. Eighteen patients were females and 12 were males. Twenty-three patients showed no glycosuria. In all patients with abnormal curves the arbitrary renal threshold was exceeded. Those with a disorder of carbohydrate metabolism were not confined to one age group but were randomly scattered.

The results and the relation to age groups are illustrated in Figs. 2, 3, and 4.

\section{Discussion}

There is a specific diabetic cataract, the 'snow-flake' cataract, but this is rare and occurs mainly in younger people. ${ }^{11}$ In older people cataract has been found to be commoner in nondiabetics than in diabetics. 1213

Other authorities have maintained a contrary viewpoint. ${ }^{14-16}$ If the asymptomatic diabetics with senile cataract are added to those cataract patients with symptomatic diabetes, the latter conclusion is fully substantiated. An abnormal carbohydrate metabolism may be associated with the aging process and could therefore be directly involved in the formation of senile cataracts. Of the $112(56 \%)$ 
patients with a normal modified standard glucose tolerance test 59 were aged 70 or over, and therefore a demonstrable disorder of carbohydrate metabolism was not responsible for their cataracts.

Van Selm $^{8}$ stated that of the 186 'incipient' cataract patients investigated by a standard glucose tolerance test over $60 \%$ showed abnormal curves. This study revealed only 71 patients $(35.5 \%)$ were asymptomatic diabetics, including those who had a positive steroid sensitised glucose tolerance test. The difference may be explained by his selection of patients. Their ages ranged from 18 to 92 , and

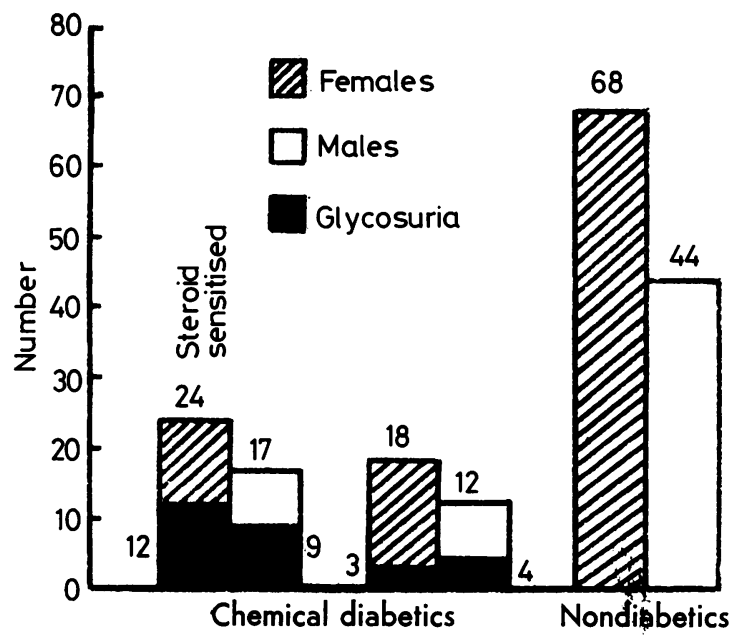

Fig. 2 Sex distribution of glucose tolerance tests' results and number of chemical diabetic patients with aglycosuria after a glucose tolerance test. patients with 'senile' cataracts were investigated only by a single test. It is pertinent to question whether 18-year-old patients can have senile cataracts, but the number of young patients was not quoted. Known diabetics were excluded, but not patients showing glycosuria or a raised fasting blood sugar. Private patients only were examined, and about two-thirds of those were female; therefore socioeconomic and sex bias was a possibility. Similar criticisms apply to Langdon's paper. The cataracts were classified as 'primary', the ages of the 100 patients varied between 44 and 70 , details of method were not included, and an undisclosed number of the 45 patients who 'showed an inability to digest the sugar meal' had an abnormal fasting blood sugar. Though patients with abnormal results were fewer than those recorded by Langdon ${ }^{7}$ and van Selm, ${ }^{8}$ the possibility of a senile cataract patient having an abnormality of carbohydrate metabolism should be considered regardless of age or body physique, as patients who have had a senile cataract extracted appear to be more likely to be diabetic.. ${ }^{10}$

Fajans $^{17}$ stated that the first signs of an impairment in carbohydrate metabolism are a shift to the right in the time of the peak and a delay in the return to normal serum values after a standard glucose tolerance test. The type of test after an abnormal modified standard glucose tolerance test was determined by values selected from a normal standard glucose tolerance test curve measured in milligrams per cent. $6 \mathrm{mmol} / \mathrm{l}$ was the nearest integer equivalent to the maximum normal fasting blood sugar of $110 \mathrm{mg}$ per $100 \mathrm{ml} .9 \mathrm{mmol} / 1$ was the nearest integer equivalent to $160 \mathrm{mg}$ per $100 \mathrm{ml}$, the maxi-

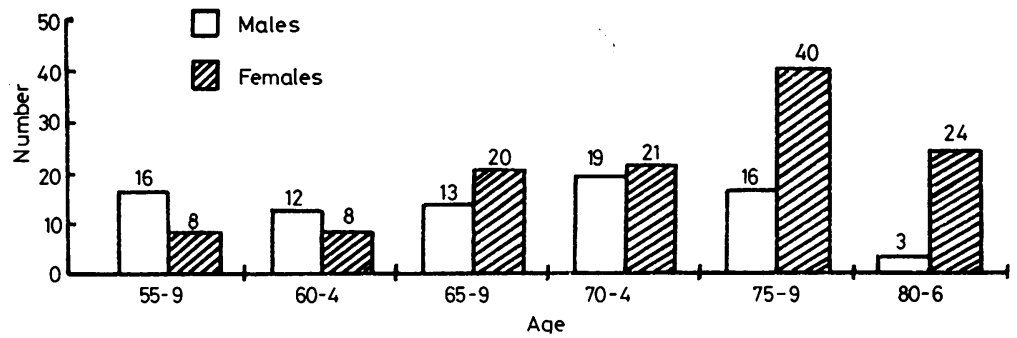

Fig. 3 Sex and age distribution of 200 patients with senile cataract.

Fig. 4 Sex and age distribution of 71 asymptomatic diabetics.

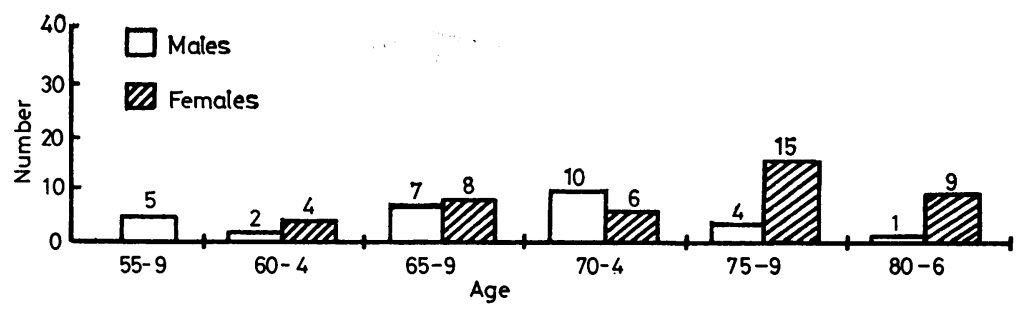


mum normal peak which should be recorded half an hour after the ingestion of glucose. Normal fasting blood glucose levels expressed in SI units are lower than those expressed in $\mathrm{mg}$ per $100 \mathrm{ml}$, and because of the fewer units to calculate SI units are less suitable for sensitive calibration.

Abnormal curves showed marked variation and the gross impairment of glucose metabolism recorded by some provocative steroid tests raised the query of the patient's possible response to a standard glucose tolerance test. The illustrated normal provocative steroid curve defines the maximum values, and many patients had lower serum glucose levels. No steroid sensitised patient had a raised fasting blood sugar with a normal provocative steroid curve. The older patients did not always have an exaggerated response to systemic steroids. The 15 negative provocative steroid tests were in patients ranging from 73 to 86 years of age. Testing for glycosuria after stressing the patient's glucose regulating mechanism by a meal rich in carbohydrate was not a reliable guide to the diagnosis of asymptomatic diabetes. Forty-three patients of the 71 chemical diabetics did not have glycosuria after drinking $50 \mathrm{~g}$ of glucose, but all the patients had a fasting blood sugar between 3.0 and $5.5 \mathrm{mmol} / \mathrm{l}$, and during the test their blood sugar exceeded $10 \mathrm{mmol} / \mathrm{l}$. Cataract patients can be effectively screened only by the simple modified standard glucose tolerance test. Its importance was shown by its leading to the diagnosis of chemical diabetes in 4 patients who had had one cataract extracted a few months prior to the test. At the time of operation urine analysis and a fasting blood sugar were normal. Clinical diabetes may occur in patients with asymptomatic glucose intolerance. They may be supervised by an ophthalmologist, preferably in collaboration with a physician who has a special interest in diabetes, though it must be stressed that future metabolic and clinical manifestations are not predictable. The effect of treatment by diet, insulin, or oral hypoglycaemics on cataract formation in an asymptomatic diabetic is unknown.

Caird et al. ${ }^{10}$ found that the development of cataract in the older diabetic was influenced by control of the diabetes. Consideration of the peculiar metabolism of the lens would support this finding. ${ }^{18-20}$ The cataractous lens of the diabetic contains sorbitol, absent from non-diabetic lenses, and higher concentrations of glucose and fructose. The inverse correlation between inositol and glucose concentrations is not so marked in the diabetic lens as in the nondiabetic lens. ${ }^{21}$ Acid metabolites, common in diabetes, encourage the release of proteolytic enzymes which denature the lens fibres and lead to opacity. It is doubtful whether lactic acid can be incriminated, because the concentration in the aqueous is identical in diabetic and nondiabetic patients (Reddy, personal communication). Hydration of the lens occurs because large protein molecules are broken down into smaller molecules, which exert an osmotic effect. The lens of an asymptomatic diabetic may be similarly affected.

Our thanks are due to $\mathrm{Mr} \mathrm{P}$. Burton and the staff of the Biochemistry Department, Burnley General Hospital; Sister J. Moore, Eye Ward, Victoria Hospital, Burnley; Mrs M. J. Hudson, personal secretary, for typing the paper, and Mrs M. J. Flintoff for the preparation of the illustrations.

\section{References}

1 Hager A. Asymptomatic diabetes in childhood and adolescence. A review. Acta Paediatr Scand 1977; 270: (Suppl) 103-5.

2 Camerini-Davalos RA, Caulfield JB, Rees SB, LozanoCastaneda O, Naldjian S, Marble A. Preliminary observations on subjects with prediabetes. Diabetes $1963 ; 12$ : 508-18.

3 Goto Y, Kato J, Takanam A, Ohneda A. Detection of prediabetes by glucose tolerance test sensitised by prednisolone. Lancet 1960; ii: 461-4.

4 Petrides P, Weiss L, Loffler G, Wieland O. Diabetes Mellitus: Theory and Management. Baltimore-Munich: Urban and Schwarzenberg, 1978: 40-3.

5 Keen H, Jarrett J. Diabetes mellitus and its complications. Medicine 1978; 2: 517-23.

6 West K. Substantial differences in the diagnostic criteria used by diabetes experts. Diabetes $1975 ; 24$ : 641-4.

7 Langdon HM. The blood chemistry of patients with primary cataract. Trans Ophthalmol Soc UK 1925; 45: 204-7.

8 Van Selm JL. Senile cataract and its relationship to the glucose tolerance curve. $S$ Afr Med J 1966; 40: 801-4.

9 Paufique L, Michaud PH. Manifestations oculaires des états paradiabetiques. Ann Oculistique 1965; 198: 1-24.

10 Caird FI, Hutchinson M, Pirie A. Cataract and diabetes. Br Med J 1964; ii: 665-8.

11 Duke-Elder S. System of Ophthalmology. London: Kimpton 1969: 11: 166-71.

12 Waite JH, Beetham WP. The visual mechanism in diabetes mellitus. $N$ Engl $J$ Med 1935; 212: 367-429.

13 Dollfus MA. Discussion du rapport. Bull Soc Ophthalmol Fr 1954; 67: 62-71.

14 Heinsius E, Arndt G, Uber Hanfigkeit des Vorkommens, Form und Genese der echten diabetischen Katarakt und Katarakt bei Diabetes. Albrecht von Graefes Arch Klin Ophthalmol 1950; 150: 555-71.

15 Kato K, Amaha E, Hagain A, Matusi M. Statistical observation on the incidence of cataract in diabetic patients. Nippon Ganka Gakkai Zasshi 1960; 64: 577-83.

16 Tulloch JA. Diabetes Mellitus in the Tropics. Edinburgh: Livingstone, 1962: 90.

17 Fajans SS. Diabetes. New York: Hoeber, 1960: 389.

18 Van Heyningen R. Formation of polyols by the lens of the rat with 'sugar' cataract. Nature $1959 ; 184$ : 194-5.

19 Van Heyningen R. The sorbitol pathway in the lens. Exp Eye Res 1962; 1: 396-404.

20 Pirie A, van Heyningen $R$. The effect of diabetes on the content of sorbitol, glucose, fructose and innositol in the human lens. Exp Eye Res 1964; 3: 124-31.

21 Pirie A, van Heyningen R. Epidemiological and biochemical studies of cataract and diabetes. Invest Ophthalmol Visual Sci 1965; 4: 629-37. 